\title{
What Use is Technology If No One Uses it? The Psychological Factors That Influence Technology Adoption Decisions in Oil and Gas
}

\author{
Ruby Roberts ${ }^{1}$, David Millar ${ }^{2}$, Luca Corradi ${ }^{2}$, and Rhona Flin ${ }^{1}$ \\ ${ }^{1}$ Aberdeen Business School, Robert Gordon University \\ ${ }^{2}$ The Oil and Gas Technology Centre, Aberdeen, Scotland
}

\begin{abstract}
What use is technology if no one uses it? This question underscores the critical interaction between people and the technology, highlighting the importance of understanding the underlying psychological factors that influence technology uptake. This study focuses on the corporate decision-makers who are the "gatekeepers" to the introduction of new technologies by their organizations. The offshore oil and gas industry has been characterized as reluctant to adopt new technology. Our thematic analysis of an interview study with 37 innovation technology stakeholders from this sector identified a set of six categories encompassing 15 psychological factors that influence the organizational decision-maker. The categories were labeled personality, attitudes, motivations, cognitive factors, social factors, and organizational factors set in a Psychological Technology Adoption Framework. This is the first attempt to focus exclusively on the main psychological factors that relate to this key decision-maker in the adoption of new technology. With further development, this preliminary psychological technology adoption framework can be used to develop interventions that support the successful technology uptake in the oil and gas business and similar industries.
\end{abstract}

Keywords: technology acceptance, innovation, decision making, adoption culture, innovation process management

Technological innovation is reshaping the global market and industrial work environments. Despite the vital importance of embracing new technology, the road to corporate adoption is not always as easy as expected. Many organizations can be hesitant to introduce new tools, systems, and digital applications, resulting in costly failures (Makkonen et al., 2016). For example, $\$ 1.3$ trillion was spent on digital transformation initiatives in 2018 with $70 \%$ of

Action Editor: C. Shawn Green was the action editor for this article.

ORCID iDs: Ruby Roberts (DD https://orcid.org/0000-0001-5420-7945; David Millar (D) https://orcid.org/0000-0002-2391-3422; Rhona Flin (iD https://orcid.org/0000-0003-4044-5699.

Acknowledgments/Funding Source: This work is sponsored by The Oil and Gas Technology Centre. The co-authors from the sponsor were primarily involved in the recruitment of interviewees as well as the design of the study and writing of the paper. The views presented are those of the authors and should not be taken to represent the position or policy of the sponsor. No conflicts of interest were identified. The authors wish to thank all those who contributed their time to take part in the interviews.

Data Availability: Data analysis methods are included in the section above and the semi-structured interview schedule is in Appendix A, however, to maintain the confidentiality and anonymity of the interviewees, as per our ethical requirements, individual data will not be made available.

Open Access License: This work is licensed under a Creative Commons Attribution-NonCommercial-NoDerivatives 4.0 International License (CC-BYNC-ND). This license permits copying and redistributing the work in any medium or format for noncommercial use provided the original authors and source are credited and a link to the license is included in attribution. No derivative works are permitted under this license.

Disclaimer: Interactive content is included in the online version of this article.

Contact Information: Correspondence concerning this article should be addressed to Ruby Roberts, Aberdeen Business School, Robert Gordon University, Garthdee, Aberdeen AB10 7QE, Scotland. Email: r.r.oberts2@rgu ac.uk these initiatives not reaching their goals, resulting in an estimated loss of $\$ 900$ billion (Tabrizi et al., 2019). While a plethora of factors will have likely influenced this outcome, the people factor has been identified as a success-critical issue (ZoBell, 2018). What use is technology if no organization adopts it?

Larger organizations have "gatekeepers" to technology adoption (Macdonald \& Williams, 1994) and they are required to make critical decisions regarding whether to introduce a new technology (Rau \& Haerem, 2010). This can be an informal or formal role in which an individual decides whether to introduce a technology and if so, how that technology will be deployed, as well as determining the criteria for its success (e.g., cost reduction by a certain percentage or performance improvement by a measure, such as time, Carlsen \& Norheim, 2003). Gatekeepers are typically managers and technical specialists who make the decisions to review or test the technologies for possible deployment in their organizations or even just to allow the vendors to make a presentation about their product to colleagues. These decision-makers are located at a critical stage within the innovation adoption process, acting as both potential blockers and facilitators (Nochur \& Allen, 1992). It is worth noting that not all gatekeepers are experts. Psychological blockers to the uptake of innovative technology can be identified across the adoption process, such as senior leaders' perception of risks to operational performance, safety managers' resistance to trialing early-stage products in their systems, and end-users' concerns about job security (Kratzer et al., 2017; Roupas, 2008). In order to facilitate the introduction of novel systems and tools, it is necessary to determine the psychological influences on technology adoption decisions in industry.

\section{Psychological Components of Innovation Adoption Decisions}

A wide range of approaches has been taken to understand the process of technology acceptance and the factors that influence it. 
This includes sociological approaches such as Roger's (1983) diffusion of innovation and information systems approaches such as the Technology Acceptance Model (TAM; Davis et al., 1989; Venkatesh \& Davis, 2000). It is interesting to note that prominent models, such as the TAM, were originally based on a psychological approach in which the Theory of Reasoned Action (TRA; Fishbein \& Ajzen, 1975) was applied to the new context of technology acceptance of IT systems. Through this model, it was understood that technology acceptance behavior was driven by prospective users' attitudes and subjective norms, formed from salient beliefs and evaluations from prior experiences. The Theory of Planned Behavior (TPB; Ajzen, 1991) was also later applied to this model to include the additional component of perceived behavioral control (Davis et al., 1989). Additional psychological factors have subsequently been added such as image, reference groups, voluntariness, experience effects, and social influence (Venkatesh \& Davis, 2000), as well as trust and risk (Pavlou, 2003). Bagozzi (2007) one of the authors of the original TAM model later criticized it for the lack of emotional, social, and cultural causal variables. Other influential models of technology adoption at the firm level (e.g., Technology, Organization, Environment [TOE]; Tornatzky \& Fleisher, 1990) make minimal reference to any psychological factors.

Within the wider literature, individual psychological factors have been identified as influencing consumers' technology adoption decision-making such as innovativeness (e-commerce; Lin \& Filieri, 2015), trust (automation, Endsley, 2017), risk perception (Frambach \& Schillewaert, 2002; Paluch \& Wunderlich, 2016), expertise (Roupas, 2008), self-efficacy (Wang \& Lin, 2012), and some attempts have been made to list these factors (Huijts et al., 2012). Likewise, for companies' adoption of cloud computing, trust in information security is considered a key variable (Schneider \& Sunyaev, 2016). Psychological factors are sometimes included as a category (along with technological, organizational, and environmental) in studies of corporate adoption decisions (e.g., Xia et al, 2019 for green technologies) but are not usually discussed in depth.

The key component that links the different approaches is the individual decision-maker who has the power to determine whether an innovation will be allowed into an organization or not. He or she will interact with the innovator or sales representative in a social exchange process, placing the human factor at the centre of the critical technology adoption gateway (Kratzer et al., 2017). There is an extensive literature on managerial judgment and decision-making in general (e.g., Bazerman \& Moore, 2017; Kahneman et al, 2011) which does consider attitudinal and social influences, as well as cognitive effects such as biases and framing). This has been applied in the study of decision-making for technology adoption, both by business researchers (e.g., Yoo \& Kim, 2018) and behavioral economists (e.g., Streletskaya et al., 2020). Consequently, the adoption decision-making process has been examined from all manner of decision science perspectives, ranging from utility theory (Shimamoto et al., 2018) and intuition (Gagnon \& Toulouse, 1996), with recent accounts suggesting that managers should balance effectual and causal reasoning when adopting new technologies (Mero et al., 2020). In this article, we do not examine the decisionmaking process per se but instead attempt to capture the broad range of psychological variables which appear to be influencing decisionmakers in technical settings, including both the individual decisionmaker and organizational-level factors.
Furthermore, there appears to be variation depending on whether individual consumer technology acceptance (Sethna \& Blythe, 2016) or organizational technology adoption is being examined (e.g., Frambach \& Schillewaert, 2002). This is relevant as organizational innovation adoption is an active behavioral process conducted by individual business consumers/industrial buyers (e.g., procurement) within their organizational context (see Makkonen et al., 2016), blurring the line between individual and organizational technology uptake. Psychological factors have also been identified at the organizational level, such as an industrial buyer's innovativeness (Steenstra et al., 2020), as well as social pressures (Roupas, 2008) and organizational culture (Radnejad et al., 2017). Consequently, industrial buyers will likely be influenced by psychological factors identified at both the individual and organizational level, shaping technology adoption decision-making.

In summary, it appears that the psychological factors are unequally distributed across models, theories, and studies of different industries with varying applications (Keupp et al., 2012; Pak et al., 2019; van Oorschot et al., 2018) which serves to create a degree of confusion. Yet, there is no comprehensive framework indicating potentially influential psychological variables for business technology adoption. In a recent bibliometric review, van Oorschot el al. (2018) identified exploration of the psychological component as the next step in advancing the understanding of the technological innovation adoption process by organizations, including a need to understand the core set of psychological variables that should be considered when examining a business decision-maker's role in technology adoption decisions. With the wave of digitalization spreading across many industries including transport, retail, energy production, and others, understanding the innovation adoption process has never been more relevant (Nambisan et al., 2019).

To address this gap, our study aims to identify the underlying psychological factors that influence business technology adoption decisions, in one sector, providing an initial framework to direct future investigations.

\section{Technology Adoption in Upstream Oil and Gas}

The upstream oil and gas industry (O\&G) explore for, and then produce hydrocarbons, often from remote and inhospitable locations, such as beneath the oceans. To cope with these hazardous and complex environments, the industry has developed and deployed a broad arsenal of technologies including robotic vehicles, data analytics, and remote monitoring software. More recently it has begun to expand into virtual/augmented reality, big data, and artificial intelligence.

Historically the O\&G industry has been highly innovative, developing and deploying a broad range of technologies. More recently, the industry has become increasingly competitive, facing challenges, such as climate change, the need to automate high-risk, error-prone tasks, and the future challenges of decommissioning (Hassani et al., 2017). Many countries, such as the U.K., are moving toward an integrated energy sector, requiring $O \& G$ to rapidly adapt to new ways of working and collaborate with other energy producers (e.g., renewables). To remain competitive, organizations need to embrace technological innovation (Porter, 1985) but this industry has a reputation for being conservative and slow to uptake new inventions (Bereznoy, 2019; Daneshy \& Bahorich, 2005; Perrons, 2014; Wood, 2014).

Effectively introducing technology within O\&G has been described as particularly challenging, given the severe operational, 
financial, and safety risks of failure, high cost of being the earliest adopter and a competitive culture (Radnejad et al., 2017; Wood, 2014). Many organizations prefer to be second or third users of technologies. This translates into the sector's slow "clock speed"the speed of change within a business environment relating to how fast an innovation is widely adopted and used within an industry (estimated as high as 16 years for O\&G; Noke et al., 2008). Similar criticisms have been leveled at other types of business being tardy and cautious to introduce new technologies, such as SMMEs (Afolayan \& de la Harpe, 2020). It is also likely that many sectors will now face analogous challenges, in the post-COVID-19 world, with uncertainty and the need for rapid transitions into new ways of working involving technological solutions (Juergensen et al., 2020). However, the $\mathrm{O} \& \mathrm{G}$ industry provides an unusual opportunity for study in that the call for improving innovation practices, including understanding how people fit into that process, came from within the industry. Evidence from $O \& G$ industry bodies indicate that psychological factors play a key role in slow technology adoption, such as risk aversion (Wood, 2014), lack of ownership and leadership around technology (Oil and Gas Technology Centre [OGTC], 2018), coupled with attitudes of reluctance to change (Oil and Gas Authority [OGA], 2018).

To address this gap, a literature review identified possible psychological factors that could influence technology uptake decisions in the oil and gas sector (Roberts \& Flin, 2020). From the few studies that considered any psychological aspects, five categories of psychological factors were mentioned. These were personality (e.g., risk aversion), attitudes (e.g., trust), social factors (e.g., social norms), cognitive factors (e.g., risk perception), and organizational factors (e.g., culture). Typically, the articles discussed organizational aspects and intervention approaches, rather than examining the factors pertaining to the individuals responsible for facilitating or blocking the introduction of new technologies.

Consequently, there does not appear to be a comprehensive framework that outlines the key psychological factors that influence technology adoption decisions in the innovation literature in general, the oil and gas literature specifically or in relation to similarly cautious sectors.

\section{Study Aim}

The aim of this interview study was to investigate in more detail the psychological factors that were identified within the literature review mentioned above, as influencing the introduction of new technology within the UKCS (United Kingdom Continental Shelf) upstream oil and gas industry. In addition, their role as barriers and facilitators will be delineated in order to facilitate the design of interventions.

\section{Method}

\section{Procedure}

The literature review indicated that new technology must go through a series of "stage gates" that normally consist of different individuals making decisions regarding the technology (e.g., to agree/decline to put a technology provider in contact with relevant personnel or to agree/disagree to a partial deployment).

To adequately sample the target population, we considered the roles (e.g., technical managers, innovation specialists, industry leaders, and end-users), types of companies (e.g., operating companies, contractors, service companies, and technology developers), and technical areas (e.g., drilling, clean energy, asset integrity, and decommissioning) with the aim of capturing a broad spectrum of experiences of introducing new technology into $\mathrm{O} \& \mathrm{G}$. Using this list as a guide, potential interviewees were then identified by the research team and were invited to participate in the study through the U.K. Oil and Gas Technology Centre contacts. While this approach may have influenced the potential sample, the initial contact list (approximately 80 contacts) was sufficiently large, covering a wide range of different roles and backgrounds to provide a representative sample. The involvement of the sponsor had the benefit of adding credibility to the study, leveraging a higher response rate than with the academic contacts alone. It also allowed for a combination of criterion and snowball (chain strategy) sampling strategies, maximizing the value of the data collected (Mason, 2017).

Once the first interviewees agreed to take part, their interviews were arranged, and permission was requested for audio recording. We continued to arrange interviews until data saturation was reached. Interviews were conducted without the presence of any representatives from the sponsor, as they were confidential and anonymous. Ethical approval was granted by the university department's ethics committee. In total, 37 interviews were completed, consisting of 20 conducted face-to-face, 6 via Skype, and 11 as phone interviews (November 2018-March 2019).

\section{Sample}

The interviewees were industry leaders $(n=5)$, senior and middle management $(n=18)$, technology adoption consultants $(n=5)$, representatives from start-up companies $(n=6)$, and end-users $(n=3)$ with a broad range of backgrounds and experience in technology adoption. Of the 37 interviewees, 11 were female and 26 were male. This included Operating Companies $(n=6)$, Contractors $(n=6)$, Service Companies $(n=12)$, Industry Bodies $(n=5)$, and Consultancy Firms $(n=5)$ as well as Others $(n=3)$ including offshore workers. Approximately half of the interviewees had experience working in O\&G outside of the UKCS and a third had experience working in other industries (e.g., metals, manufacturing, and IT). The interview sample had a wide spatial diversity of participants working in the U.K., the Netherlands, Denmark, Norway, France, and the United States.

The interviewer became aware that similar themes were being identified and discussed during the interviews and after 37 interviews, no new data were being found that suggested an additional conceptual component (Glaser \& Strauss, 2017). Consequently, it was decided that data saturation had been reached and therefore no additional interviewees were required. Determining saturation included keeping informal notes of potential themes, actively looking for additional themes during the interview process and initial analysis stages, and sampling a wide range of experiences and backgrounds related to technology innovation (Faulkner \& Trotter, 2017).

The average interview length was $52 \mathrm{~min}$ with a range of 40-70 min. The total interview time was $27 \mathrm{hr}$ and $35 \mathrm{~min}$.

\section{Interview Schedule}

The aim was to identify the psychological factors that influence technology adoption decisions by organizations. With this in mind, 
a semistructured interview schedule was developed which is shown in Appendix A. This consisted of broad questions about the individual's roles and experiences in relation to technology adoption in O\&G. Given the relevance to decision-making, aspects of the critical incident method (Flanagan, 1954) were used to structure part of the schedule, relating to the questions identifying and discussing examples of successful and unsuccessful technology introduction. There was a focus on what interviewees perceived to influence these outcomes and what was learned from them.

As the interview was semistructured, it allowed the use of followup prompts where required. This approach provided the opportunity to gather rich data which could be used to advance understanding and develop empirically grounded arguments (Corbin \& Strauss, 2014). The interview schedule was piloted with five technology innovation managers and the schedule was refined to include questions regarding how interviewees understood the terms deployment and adoption.

The interviewer was an industrial psychologist with a broad experience of conducting interviews both within $O \& G$ and in other sectors (e.g., healthcare). However, there was less familiarity with start-up technology terms (e.g., value proposition) and in some instances, this was valuable (e.g., asking what a term meant could lead to interesting discussions about how the interviewee interpreted these terms).

\section{Data Analysis}

The interviews were recorded, and notes were taken. The coauthors from the sponsoring company did not have access to the interview transcripts and were not directly involved in the analysis process, limiting their influence on the study's findings.

Once transcribed, the interviews were entered into Nvivo 11 (QSR International, 2013) to facilitate the analysis process. Nvivo is a software program that enables sections of interview transcripts and the themes that they contain to be coded and tracked while maintaining access to the source data (Bazeley \& Jackson, 2013). Examination of the interview transcripts did not show any discernible differences in interview quality or topic discussion between the different interview mediums (e.g., face-to-face, Skype, or phone call), although these can have relative advantages and disadvantages (Opdenakker, 2006). Using a combination of these mediums was intended to compensate for the different disadvantages and address the practical limitations of data collection.

The transcripts were deductively analyzed within the Nvivo software using Braun and Clarke's (2006) Thematic Analysis, a method previously used to study technology acceptance (Sepasgozar et al., 2018). This version of thematic analysis entails a six-step iterative, structured method for identifying, analyzing, and reporting themes within the interview material. The first step was familiarization with the interview transcripts, then Step 2 involved the systematic review of the data and the initial production of codes to represent psychological factors. At this stage, items of data were coded with many codes that appeared to fit the data until definitions had been determined. A total of 38 codes was identified and is available in Appendix B. Step 3 involved sorting through these codes to identify overarching themes within the data and the broad psychological factors that appeared to influence technology adoption, including how these themes are related to each other. The related codes were collated under relevant themes - these became the initial categories outlined in the Results section. Step 4 involved critically reviewing the codes, how they relate to each other and ensuring that the thematic map fits with the data set. This involved collapsing multiple themes which were not conceptually different together, resulting in a refined taxonomy of 20 nodes (psychological factors). This included developing working definitions of the categories and nodes (psychological factors) which could be used as part of the interrater reliability (IRR) test. Step 5 defined the psychological categories and factors before conducting the IRR (see below) and Step 6 was writing up the results.

A key stage between Steps 5 and 6 was to conduct the interreliability test. While there are criticisms of testing rater reliability within qualitative research (e.g., Stenbacka, 2001), it can be valuable to consider the reliability of the coding. To assess IRR, a second coder (also an industrial psychology researcher with experience of coding and of the oil and gas industry) was given a section of transcript text not included in the analysis to practise coding with the advice of the first coder. Then, following guidance on the degree of double coding required (Barbour, 2001; O'Connor \& Joffe, 2020), the second coder was given six transcripts from the full set to code independently using the coding framework of categories and factors developed in Step 5, as well as Mayring's (2004) coding rules for content analysis. The coders had been instructed to remain open for new and alternative factors. The two coders' sets of coding were compared to calculate IRR which assesses the degree to which different raters give a consistent allocation of codes for the same material. Cohen's (1960) kappa coefficient was calculated and found to be acceptable (0.81; Fleiss, 1981). The Kappa calculation is given in Appendix C. Therefore, the remaining transcripts were only coded by the first author. The thematic analysis resulted in an initial framework of the psychological factors that influence technology adoption in the $\mathrm{O} \& \mathrm{G}$ industry shown in Table 1 .

The analysis also included identifying the psychological facilitators and barriers that the interviewees experienced. Derived from the factor set, some advice on psychological facilitators and barriers was prepared with relevant quotes from the interview material (Results section 4.8).

\section{Data Availability}

Data analysis methods are included in the section above and the semistructured interview schedule is in Appendix A, however, to maintain the confidentiality and anonymity of the interviewees, as per our ethical requirements, individual data will not be made available.

\section{Results}

The analysis ${ }^{1}$ of the interview data revealed, six categories, labeled personality factors, attitude factors, motivation factors, cognitive factors, social factors, and organizational factors with 14 factors identified as influencing the introduction of new technology into the UKCS O\&G industry. This set echoed the psychological factors identified within the technology adoption literature and the barriers highlighted in the O\&G industry (OGTC, 2018; Roberts \& Flin, 2020; Wood, 2014). The categories, factors, and total number of times they were mentioned by the interviewees during the interviews are

\footnotetext{
${ }^{1}$ A preliminary report of the analysis while data collection was still in progress was presented at the Human Factors and Ergonomics Society conference (Roberts \& Flin, 2019).
} 
Table 1

The Preliminary Psychological Technology Adoption Framework is Represented by the Categories and Factors. The Table Also Shows the Number of Times Each Factor was Mentioned in the Interviews in Total and Per Interviewee

\begin{tabular}{|c|c|c|c|}
\hline Category & Factor & $\begin{array}{l}\text { Total No. of } \\
\text { times coded } \\
\text { across } \\
\text { interviews }\end{array}$ & $\begin{array}{c}\text { No. of } \\
\text { interviewees } \\
\text { who mentioned } \\
\text { factor }(x / 37)\end{array}$ \\
\hline \multicolumn{4}{|l|}{$\begin{array}{l}\text { Personality } \\
\text { factors }\end{array}$} \\
\hline & Innovativeness & 69 & 18 \\
\hline & Risk aversion & 37 & 11 \\
\hline \multicolumn{4}{|l|}{$\begin{array}{l}\text { Motivation } \\
\text { factors }\end{array}$} \\
\hline & Personal incentives & 149 & 27 \\
\hline & $\begin{array}{l}\text { Fear of technology } \\
\text { failure }\end{array}$ & 33 & 14 \\
\hline \multicolumn{4}{|l|}{ Attitude factors } \\
\hline & $\begin{array}{l}\text { Technology } \\
\text { attitudes }\end{array}$ & 88 & 23 \\
\hline & Trust & 42 & 14 \\
\hline \multicolumn{4}{|l|}{$\begin{array}{l}\text { Cognitive } \\
\text { factors }\end{array}$} \\
\hline & Risk perception & 77 & 24 \\
\hline & $\begin{array}{l}\text { Technical } \\
\text { knowledge }\end{array}$ & 73 & 25 \\
\hline & $\begin{array}{l}\text { Perceptions of } \\
\text { certainty }\end{array}$ & 42 & 15 \\
\hline & $\begin{array}{l}\text { Previous } \\
\quad \text { experience }\end{array}$ & 17 & 14 \\
\hline \multicolumn{4}{|l|}{ Social factors } \\
\hline & Social influence & 68 & 19 \\
\hline \multirow{2}{*}{\multicolumn{4}{|c|}{$\begin{array}{l}\text { Organizational } \\
\text { factors }\end{array}$}} \\
\hline & & & \\
\hline & Leadership & 95 & 23 \\
\hline & $\begin{array}{l}\text { Collaboration } \\
\text { culture }\end{array}$ & 52 & 20 \\
\hline & $\begin{array}{l}\text { Technology } \\
\text { adoption } \\
\text { culture }\end{array}$ & 116 & 18 \\
\hline
\end{tabular}

shown in Table 1. It can be seen from these data that motivation, innovativeness, technology attitudes, risk perception, technical knowledge, and social influence were key individual factors and that leadership and technology adoption culture were key organizational factors. Frequencies are only shown for interest to indicate how often a factor was mentioned overall and cannot be interpreted as a weighting. A factor may not have been mentioned frequently if thought by interviewees to be obvious, unimportant, or of a sensitive nature. Selected interviewee quotes are given in Table 2 to illustrate the psychological factors identified and showing their interrelatedness.

These findings were used to build a preliminary framework of the psychological factors that influence technology adoption in oil and gas - the Psychological Technology Adoption framework. An overview of the framework is followed by a full description of each of the factors including definition and illustrative quotes.

\section{Psychological Technology Adoption Framework}

The focus of the research was on technology adoption, in particular on the psychological factors that influence corporate decisions within one industrial sector (upstream oil and gas). Psychological is defined as pertaining to mind and behavior and our primary unit of analysis was the individual decision-maker (typically the corporate buyer or his/her representative). This focus framed our data collection, analysis, framework development, and factor labeling. The factors relate to various stages of adoption decisions, for example, a precursor decision to grant access to a technical or operational manager, inviting a start-up technology company to give an internal presentation to a potential client, or deciding to agree to a field trial (see also Afolayan \& de la Harpe, 2020).

The framework is primarily intended for practitioners, but could also be valuable for academics, consequently, it requires a straightforward structure and accessible language, as well as a robust scientific basis. In addition, to support usability, it should not be too long or overly complicated. With these specifications in mind, the data were examined to better understand and represent the underlying psychological factors that influence technology adoption. The factors were allocated to categories-four categories are at the individual decision-maker level (e.g., attitudes) and one is at the organizational context level. It was found that some factors within these two levels overlapped (e.g., organizational incentives influenced individual motivations) but were sufficiently separate to warrant their allocation at different levels, in line with previous innovation frameworks (Frambach \& Schillewaert, 2002).

The labeling and definition of the main categories and component factors shown below were based on the terms used for these psychological constructs in the American Psychological Association Dictionary of Psychology (American Psychological Association n.d. https://dictionary.apa.org/psychology) and the psychological literature. Some of the factors (e.g., technical knowledge) have been labeled using terms already applied to the concept by the oil and gas sector, in which case, the psychological term is given in the definition.

The data indicated that many of the factors appear to be interrelated. It is likely that personality factors, such as innovativeness will influence technology attitudes, risk perceptions, and leadership (which will likely influence culture). Motivations were identified as a key influencing factor and it is likely that they influence technology adoption decision-making at the individual (e.g., promotion and career progression) and organizational level (e.g., incentives and organizational culture priorities). Furthermore, it is likely that there is a two-way influence between attitudinal factors and cognitive factors (e.g., attitudes will likely influence risk perceptions and vice versa). This will also occur within categories such as leadership's influence on both technology adoption culture but also collaboration culture.

Each category and factor are defined with a brief overview in the following sections.

\section{Personality Factors}

Personality (Category): Individual differences in configuration of characteristics and behavior that encompass an individual's adjustment to life, including major traits, interests, drives, values, self-concept, abilities, and emotional patterns (American Psychological Association Dictionary). There are two component factors relating to technology adoption: innovativeness and risk aversion. 
Table 2

The Categories and Factors Identified From the Interview Transcripts With Illustrative Quotes (Interviewee Number)

\begin{tabular}{cc}
\hline Factors & Quotes (interviewee number) \\
\hline
\end{tabular}

Personality factors Innovativeness

Risk aversion

Attitudes

Technology attitudes

Trust

Motivation factors

Personal incentives

Fear of technology failure

Cognitive factors

Risk perception

Technical knowledge

Perceptions of certainty

Previous experience

Social factors

Social influences

Social norms

Organizational factors Leadership
But if you're doing innovation, you need to be okay to say, I don't know. I need to investigate; I need to experiment. So that's what I meant about the mindset of embracing the unknown. (18)

We need to move away from the old dinosaurs, like myself, and get these bright young things who are used to technology, who are used to trying new things, and who know how the cloud works. (1)

He was quite into technology and was quite collaborative and had a lot of initiative in terms of moving things forward. And he was a bit of a radical in terms of making things happen. (22)

There is a tendency to fairly risk-averse views about technology. (30)

But there's entrenched views in there, there's a huge bit of risk averseness in there (17).

There's a sense around that we can't accept any risk whatsoever and we've seen it on the HSE side. (16)

So, some of those engineers will be hostile, nonreceptive, like "what is this? A: I don't know what it is, so I can't understand it. B: I'm sceptical that it produces anything. C: Are you trying to tell me you're smarter than me? D: Are you trying to tell me you know my asset more than I do?" (10)

They're really enthusiastic about it and it will help them truly make better decisions and understand what's going on in the world better, and, yeah, that kind of enthusiasm, if we can deliver on it, will keep pulling these ideas through. (13)

I can imagine people saying no, not because they are against being monitored in this risky environment but because they're worried about where it will go. And it's probably made worse now that we're in a more technologically focused area where people are suspicious of information being gathered. (34)

you know trust was being lost between the supplier and the MOD because the supplier looked like they were delivering an inferior product. (15)

"That's probably one of the biggest barriers, "what does it mean for me? Does it mean I'm going to be out a job if I adopt this system?" (I6)

there is almost nonincentive for them to adopt new innovations and new technology because if it is not broken, don't fix it. (15)

The fear of failure is one of our worst barriers but if we can, instead of being fearful of failure, if we can turn that around and look at it from a point of view if that didn't work, why not? Okay, let's make sure we share that now so that no one else repeats that same error, mistake, and experiment. Then it ceases to become a fear of failure, it becomes a willingness to explore. (1)

Also for management principles, there's a huge gap there where people feel like they need to be in control and where, if you fail, it's never seen as something positive. (17)

So, some risks are perfectly acceptable. I am quite willing to internalize and take on board and be accountable for some risks. Others, no thank you, too much out of my comfort zone. (10)

Where a client may see a lot of risk and a lot of concern, of which a lot of it is very justified. And the entrepreneur is very excited and enthusiastic and sees all of the benefits that they want to share. (21)

There's a handful of them around the world of this nature. So we certainly don't have the expertise in-house. There's a few of us in the business who have worked throughout the industry for long enough to know some smart people. They do have their expertise. (19)

They can understand where technology fits in the process of running a platform, but it wouldn't occur to them to look at a new technology and say "well, if we applied this it would benefit the wells guys," because it's just not where their knowledge base is. (14)

It's the fear and the uncertainty and all this mountain of information that you've got to deal with, it just freezes them so they can't move forward. (16)

It's a very high-risk industry and we have a natural reluctance, I think, within the industry, to accept and adopt new technology because we know what works, we think we know what works well, so we stick with what we know. (26)

I think we quite often find when we talk to people that they get really excited about technology and they give you lots of positive feedback on ideas, but then it never goes anywhere because they haven't really thought about what they would have to change to implement it. (9)

Your own perspective or own baggage can influence how you think things are. (6)

It all depends on the level of relationship that's built up between the suppliers and the operator. My experience is, I work very hard on those relationships so that they're as open and honest as they can be and that's led to very much team success for everyone. (26)

Deployment is done by a virtual community or team, if you like, of work through others organizing it right across the formal organizational departments, or different companies. (5)

That's a real key thing in terms of moving forward. You've got to have someone who's respected by the troops and can talk their language in terms of what impact this may have. (22)

It's a way of perhaps hiding a lack of competence, or a lack of a safe space to say, "I don't know." (I9)

You've got the traditional "these are the offshore guys, these are the onshore guys" and they are expected to behave in a certain way. (28)

What generally happens is if the leadership is strong enough and it's "this is something the business wants to do, guys, get on with it," you go through a bit of resistance and then you get a couple of quick wins where they go "shit, wow. We'd never have done that." (10)

It's still early days but we have seen some very significant commitment from our senior leadership team in terms of resourcing. (21) 
Table 2 (continued)

\begin{tabular}{|c|c|}
\hline Factors & Quotes (interviewee number) \\
\hline Collaboration culture & $\begin{array}{l}\text { So I think one of the big problems with oil and gas again is a kind of tendency, to kind of look internally and only look to } \\
\text { immediate competitors, and not actually look to other industries to see what they're doing and how can we translate their } \\
\text { experience. (20) } \\
\text { It's about breaking down the silos. (15) }\end{array}$ \\
\hline $\begin{array}{l}\text { Technology adoption } \\
\text { culture }\end{array}$ & $\begin{array}{l}\text { But culture is something that keeps you safe and keeps you down the same track, isn't it? And gives you your job and, "This is } \\
\text { just the way we do it around here." }(21) \\
\text { So, we get over the freedom to fail and reward for trying, share the lessons, adopt that culture. And then we can get happier getting } \\
\text { comfortable outside our comfort zone and stepping into that slightly unknown. (1) } \\
\text { It's great to see that new technology has really been part of the core strategy of the company and everybody lives and breathes this. (2) }\end{array}$ \\
\hline
\end{tabular}

\section{Innovativeness}

Innovativeness relates to the individual's orientation toward novelty and change (Aldahdouh et al., 2019; Hurt et al., 1977). This includes his or her willingness to try out new technologies (both in personal life and work life). Ranges from a preference toward staying with traditional ways/current situation in preference to experiencing novel approaches.

There does not appear to be consensus on the meaning of innovativeness within the innovation literature (Hauser et al., 2006) with definitions ranging from a predisposition to learn about and adopt new products (Goldsmith \& Hofacker, 1991) or a risktaking propensity with an ability to cope with uncertainty (Agarwal \& Prasad, 1999) or a receptivity toward change (Hurt et al., 1977; Leonard-Barton \& Deschamps, 1988) to trying new things (Bartels \& Reinders, 2011). Therefore, within our allocation of material to this factor, it was decided to consign openness to change items to innovativeness. The term innovativeness is more readily recognized within the O\&G industry in relation to technology adoption, compared to openness to change.

In the data set, innovativeness was considered to be "very open to new kinds of ideas and ways of doing things, particularly if it'll help their business" (Interviewee 21), not only showing innovativeness in their personal life but in the context of workplace technology decisions. For example: "Which means that we can have really incredibly innovative people in their personal lives who go and do amazing stuff and more often own two or three second businesses on the side. But when they come to do innovation at work, are a lot more conservative and risk averse." (Interviewee 20)

\section{Risk Aversion}

The tendency, when choosing between alternatives, to avoid options that entail a risk of loss, even if that risk is relatively small (American Psychological Association Dictionary). This includes his or her risk-taking propensity and will influence the likelihood of introducing a high-risk technology.

Our data indicated that risk aversion was sufficiently separate from innovativeness to warrant being a distinct factor. This is reflected within the broader business literature (e.g., SaunerLeroy, 2004) and is understood within the O\&G to be related to safety management. In line with the risk literature (Deery, 1999; Hunter, 2002), risk aversion (tolerance) was categorized as a personality trait whereas risk perception (see below) was set as a cognitive factor.

\section{Attitude Factors}

Attitudes (Category): Mental evaluations that an individual forms about people, objects, events, or ideas, which can influence subsequent behavior. Attitudes have three components: affective (emotions about the object); conative (influence on behavior and actions toward the object); and cognitive (beliefs and knowledge about the object; Ajzen \& Fishbein, 2005; American Psychological Association Dictionary).

\section{Technology Attitudes}

The evaluations that an individual makes about novel technical products including the people, objects, events, and ideas associated with their adoption (Edison \& Geissler, 2003). This will include the beliefs that they have about the result of performing a behavior associated with introducing a new technology.

Technology attitudes were identified as a key influencing factor. Developing and cultivating a positive technology attitude in which innovation was perceived to be valuable to the team, department, organization, or industry was identified as a key success factor. Nevertheless, this was often contrasted against deep-rooted scepticism that the technology would not work, often because technology regarded as similar had failed previously. An example of negative technology attitudes was the "Not Invented Here" syndrome in which individuals, teams, or companies are unwilling to try new ideas or technologies from external companies or locations as they believe that they may be of inferior quality was found to negatively influence technology attitudes. Early engagement and creating a sense of ownership are required to foster a positive technology attitude.

\section{Trust}

Belief that an individual has toward people (or objects) regarding their ability, reliability, and truthfulness (Demolombe, 2004). In this adoption context, trust is a belief about not only the technology, but also all the stakeholders involved (e.g., the developers, managers involved in adopting new technology, leadership; Ratnasingam, 2005). Trust is particularly important where there is risk or uncertainty involved (e.g., unknown company or technology).

Trust was a critical factor for technology introduction between all stakeholders involved in the decision-making and adoption process including developers, potential clients, managers, and end-users. "People can be very mistrusting of anything that's new. Whether it's going to make their life easier or not, people are generally quite mistrusting of change or anything that's unknown to them." (Interviewee 19) 


\section{Motivation Factors}

Motivation (Category): The impetus that gives purpose or direction to behavior and operates in humans at a conscious or unconscious level (American Psychological Association Dictionary); underlying needs (e.g., physical, emotional, cognitive) that influence an individual's attitudes and behaviors (Herath, 2010).

\section{Personal Incentives}

Perceived rewards or punishments (to be avoided) acting as drivers for behaviors. In relation to adopting new technology, examples of motives relating to personal incentives can include desires to improve job performance, pay or promotion (Gagné \& Deci, 2005), or to avoid redundancy. They drive attitudes, behaviors, and risk perceptions. There are distinctions between intrinsic motivations (e.g., pleasure) or extrinsic motivations (e.g., tangible rewards, such as a bonus).

Personal incentives (positive or negative) were perceived as strong influencing factors on technology decision-making. In some instances, these motivations were explicit, such as how a successful introduction might be recognized. However the incentives could be more subtle, involving concerns over job security, conflicts with internal projects, budgets, and workers' reactions concerning personal privacy: "Big offshore guys sitting in workshops saying, "I'm not having xxxxx Big Brother looking over my shoulder"” (Interviewee 14).

\section{Fear of Technology Failure}

Refers to the motives and concerns about the consequences of introducing a new technology and its potential failure. These motives are similar to fear of failure when risk taking (Atkinson, 1957), often applied in a business context (e.g., Cacciotti et al., 2016) although in this case, relate particularly to the operational consequences than personal implications for the decision-maker. They can include concerns regarding safety consequences of the technology failing, the impact a technology may have on operational performance if it fails (e.g., cost or lost production time). For example, one respondent said that the consequences of a technology failing could be "catastrophic and the legacy of things like Piper Alpha $^{2}$ stick so firmly in people's minds" (Interviewee 13). This fear manifests itself at an individual, organizational, and industry level with "the biggest handbrake in adoption of innovation and technology in the oil and gas sector is this absolute refusal to be the person to go first" (Interviewee 15). Recognizing that not all innovations will succeed and having the space for innovations to fail were identified as being a key facilitator for introducing new technology (e.g., partial deployment in lower risk situations).

\section{Cognitive Factors}

Cognitive Factors (Category): Mental processes that drive knowledge and understanding of the world, including attention, perception, memory, language use, and problem-solving (Amercian Psychological Association Dictionary). Several cognitive factors including risk perception and judgments of uncertainty, memories, and decision-making influence technology adoption.

\section{Risk Perception}

Risk perception is an individual's subjective assessment of the level of risk associated with a particular hazard (American Psychological Association Dictionary); it involves gathering information and making a judgment of the risk level, and potential loss that could be incurred, in a given situation. Risk perception is different from, but may be affected by, tolerance of risk (Slovic, 1987 and see risk aversion, above). Risk perception does not necessarily equate to objective risk and is influenced by previous experiences, attitudes, motivations, expertise, and culture. Risks that are of concern here can be both individual risks (e.g., loss of reputation, job security, or financial rewards) and organizational risks (e.g., financial, performance, and safety consequences) if the adopted technology fails.

Risks at the individual level (e.g., loss of reputation, job security, or financial rewards) and organizational level (e.g., financial, performance, and safety consequences) were identified for both. This included risks if the technology fails or succeeds. "This is an industry that has to operate with the highest degrees of safety and predictability. As people say, if something goes wrong with Apple, you may not be able to make calls for a day, or your phone won't respond. If you mess up in our industry, people die." (Interviewee 18).

There appeared to be a net value or risk calculation influencing risk perception and subsequent decision-making. While a technology may offer considerable value in terms of performance, safety or financial savings should it work, this had to be judged against the estimated consequences of it failing. This perceived net risk-value comparison has the potential to act as a psychological barrier. Interviewees also pointed out that there were differences in which risks were organizationally acceptable and those which were not (e.g., lack of standard operating procedures). Providing thorough evidence of testing an innovative product in a range of environments and scenarios was required to reduce perception of risk. Perceptions of uncertainty and familiarity influence risk perception and technology decisions, particularly when a radical innovation offers net advantage but there are not standard measurement tools to manage the associated risks and uncertainty.

\section{Perception of Certainty}

The sense of surety that an individual has about the prediction of current or future events and states (e.g., decisions or actions). It refers to the judged level of confidence about how the technology works, the developers, how it will be introduced, and whether it will be successful (Johnson \& Slovic, 1995).

\section{Memory of Previous Experience}

Recollections of positive and negative experiences with technology and new ways of working (Agarwal \& Prasad, 1999), will influence risk perception and subsequent decision-making. Poor previous experiences with new technology can negatively frame risk judgments and impact technology decisions.

\footnotetext{
${ }^{2}$ Piper Alpha was an oil production platform in the North Sea. An explosion and resulting oil and gas fires destroyed the platform, killing 167 people on the July 6, 1988 (Cullen, 1990). Subsequent investigation into the disaster resulted in industry wide changes to the safety regime and culture.
} 


\section{Technical Knowledge}

Refers to the process of an individual recalling their domainspecific knowledge which contributes to his or her performance (Agarwal \& Prasad, 1999). Knowledge refers to the state of being familiar or aware of the existence of something and can represent one's range of understanding in relation to it. It is built up through technical learning and hands-on previous experience and is a fundamental basis for more accurate risk perception and decision-making.

This was understood to be strongly related to risk perceptions and uncertainty. Maintaining essential expertise to be able to accurately assess the risks and advances of technology, requires significant resources. However, with the rapid rate of technological development both in and out of the industry, it can be difficult to realistically maintain expertise. Where expertise was lacking, accurate risk perception was hindered. Operators and suppliers alike are beginning to recognize the importance of education and expertise around new technology, reducing risk perceptions and uncertainty.

Competence is absolutely fundamental and then there's a whole new set ... You've got the kind of people who don't want to take the technology because they're a bit scared of it and maybe they don't know it and they don't understand, don't know how to use it. (Interviewee 20)

\section{Social Factors}

Social Factors (Category): Refers to what can be called social cognition, in which people perceive, think about, interpret, categorize, and judge their own social behaviors and those of others (American Psychological Association Dictionary). This includes the effects of role models and group membership (e.g., Status and hierarchies).

\section{Social Influence}

Any change in an individual's thoughts, feelings, or behaviors caused by other people (American Psychological Association Dictionary). This presence may be real, imagined, expected, or implied. These people include those in personal and professional networks, role models, opinion leaders, and social hierarchies were found to influence attitudes, behaviors, and intentions to use new technologies. Peer group pressure can also affect technology decisions (e.g., if others are starting to use this technology, a decision-maker may be more open to the possibility of introducing it). Examples of social influence on technology decisions include product champions (individuals who are well respected within their field, can use the right language to sell the value proposition and potential impact of the technology, buy into the product, and have an extensive network; Markham \& Aiman-Smith, 2001).

Social influences and relationships such as personal and professional networks, role models, and social hierarchies were found to influence attitudes, behaviors, and intentions to use new technologies. Using these social relationships as leverage was found to be an effective way of influencing responses to technology. While product champions were recognized as important, it was also pointed out that a well-connected and respected individual has the potential power to jeopardize a project. "There's nothing worse than having somebody who is just sniping from the back but has influence" (Interviewee 6). Furthermore, a lack of social contacts and social influence can make it difficult to break into the industry- "If you're a brand-new person, totally unknown, you would probably struggle to get in without actually knowing people" (Interviewee 30).

\section{Subjective Norms}

A perception that an individual has regarding whether people important to that individual (e.g., colleagues and supervisors) believe that he or she should or should not perform a particular behavior (Ajzen, 1991). Subjective norms can influence technology acceptance via the motivation to maintain a favorable image within a reference group. In this context, image refers to the degree to which the innovative technology is perceived to either enhance or diminish an individual's social status (Moore \& Benbasat, 1991). For example, not being able to speak out about a technology that you are concerned about because the perceived norm is to agree with the innovation manager.

\section{Organizational Factors}

Organizational Factors (Category): This refers to the psychological factors that occur at the organizational level. An organization being structured entity (e.g., in business, industry, and services) consisting of various components that interact to perform one or more functions. (American Psychological Association Dictionary).

\section{Leadership}

The values, behaviors, and attitudes (e.g., toward change, technology, long-term/short-term vision) of people in all positions of leadership (e.g., line managers, senior supervisors, managing directors, and chief officers) and how these influence the organizational culture and behaviors of employees (Northouse, 2018). This includes leadership characteristics relating to innovativeness and having a vision of the organization for the future and how technology fits into that (e.g., Hameed et al., 2012).

Leadership drives the organizational and technology adoption culture via their attitudes, incentives, and priorities as well as having a long-term vision of technological innovation within the organization. Leader characteristics can have a significant influence on how an organization responds to technology (e.g., background, attitudes, personality traits, risk perceptions, and expertise). Leaders' and their organizations' priorities will likely shape how behaviors are incentivized and rewarded. This includes how success is measured, such as cost cutting or value creation, and how people are measured against this in the context of innovative technology (e.g., key performance indicators, number of patents filed). While no significant differences were identified in terms of the psychological factors that leaders discussed, it was noted that there was a marginal trend for more senior interviewees to discuss technology adoption at an organizational level. For example, organizational culture was frequently mentioned by senior individuals (e.g., chief executives) compared to individual-level factors such as attitudes or cognitive factors. 


\section{Collaboration Culture}

The specific aspect of organizational culture relates to how people internally and externally work together to reach a shared goal (Dodgson, 2018). This would include the social norms, standard practices, strategies, and leadership surrounding collaboration. Collaboration culture includes the willingness to share knowledge, competencies, and experiences with other parties (both internally, for example, between departments and externally, for example, with other companies).

Given that to introduce technology successfully requires a range of people from different teams, departments, and companies, creating a collaboration culture is an important facilitator. This encompasses sharing of knowledge, expertise, and resources to work together for a larger goal, as opposed to individual targets. Collaboration culture and willingness to be internally open about new technology will influence and interact with the technology adoption culture.

\section{Technology Adoption Culture}

The specific aspect of organizational culture relates to how technology and innovation are valued within an organization (Frambach \& Schillewaert, 2002; Kratzer et al., 2017). This would include the social norms, standard practices, risk taking practices, procedures (including procurement), priorities, incentives, organizational openness to change and access to resources. This includes several components that directly and indirectly influence the technology culture such as norms, priorities, and way of working with new technology but also the safety culture, blame culture (and how this creates a fear of failure/or failure culture-how does the organization behave and respond to potential and real failure), organizational priorities and wider values.

This factor was identified as influencing the entire development and adoption process as well as interacting with the other psychological factors (e.g., motivations, attitudes, and risk perception). This refers to how technology is valued and perceiving it to be a part of organizational priorities, strategy, and the core business. This was also related to the organization's level of innovativeness (e.g., openness to innovation within the organization), how it copes with failure and uncertainty (e.g., blame culture or learning culture), and how resources are allocated. Assuming that not all technology will be successful, a healthy adoption culture included having an allowance for failure in which it was accepted that some technologies would not reach their projected success (e.g., they could technically work but may not produce the anticipated outcomes).

\section{Psychological Facilitators and Barriers}

From the material used to identify the factors, there were specific examples of actions that were thought to either facilitate or obstruct positive technology decisions within the UKCS oil and gas industry. The facilitators and barriers are listed below and the psychological factors which they are associated with are shown in brackets, where appropriate, support quotes are given.

Psychological facilitators include:

- Identification and involvement of product champions both internally and externally to the adopting organization (social influences).
If you've got somebody that is a champion for you, that's pulling it through, because he has been involved at the outset. And he knows the benefit it is going to provide it to him at work. Then he's going to go out and sell it for you. (Interviewee 24)

- Early end-user engagement to create buy-in to the technology as well as potentially providing feedback that can be used to improve the innovation (social influences).

First raise awareness, identify the guys that are at the same time an end user and interested, and wanting to participate. And wanting to associate them as a step-by-step to the process of reflection and designing. (Interviewee 31)

- Fostering a sense of trust between key stakeholders, including developing relationships between developers and potential clients (trust).

So, it's an iterative process of increasing trust, increasing credibility, of the device, of the technology, of the people. (Interviewee 6)

- Articulating a clear value proposition, including the net risk value, and educating prospective clients about it (risk perception \& technical knowledge).

I think in some cases it's the value of the reward against the perception of risk. Communicating that value proposition that it's offering and communicating that to your clients. (Interviewee 32)

- Developing a broad professional peer community to share lessons and encourage technological collaboration (social influence \& collaboration culture).

So, they were keen, we got [company] connecting with [company]. We got other companies involved. Ten companies signed up to try this out and trying it out in offshore wells. (Interviewee 22)

Psychological barriers include:

- Negative technology attitudes and motivations in which the introduction of the product or service is perceived to be conflicting with own priorities (technology attitudes).

I think in oil and gas, and in general, what I see is a framework where you only reward success. You only reward the people that got it right, you don't reward people for trying to do things differently. You won't have a big change if people don't try things differently. (Interviewee 19)

- Poor credibility of unproven technologies, individuals, or organizations, particularly at the start-up stage (trust).

I think that was sort of the key thing for me was that it was the loss of faith, the loss of trust in the system and I think they would have been much better in taking a longer time to develop it and to test it to run through it, so that they got a better initial product, rather than trying to roll something out too fast. (Interviewee 15) 
- Leadership that takes a short-term approach in which technology is perceived to only add value in the immediate context (leadership).

I'm pretty disappointed in our leadership team. They're a pretty senior level, and they don't see the value it in for the longer term. (Interviewee 13)

\section{Discussion}

What use is new technology if no one adopts it? This question underscores the critical interaction between people and the technology that they are considering for corporate adoption, highlighting the importance of understanding the underlying psychological factors that influence their decisions.

\section{Psychological Technology Adoption Framework}

Our preliminary psychological technology adoption framework consists of 15 factors: personality (innovativeness and risk aversion), attitudes (technology attitude and trust), motivations (individual motivations), cognitive factors (risk perception, technical knowledge, perception of certainty, and memory of previous experiences), social factors (social influences and subjective norms), and organizational level factors (leadership, technology adoption culture, and collaboration culture). The factors identified for O\&G within the interview results reflect those found in a literature review of this sector (Roberts \& Flin, 2020) and mentioned by O\&G industry bodies (e.g., OGA, 2018; OGTC, 2018; Wood, 2014). They are also similar to the psychological factors included in other frameworks of technology acceptance for personal consumers (Huijts et al., 2012) as well as in more general psychological models of behavior change (Michie et al., 2011). Overall, the results underline the central role that people play within the processes involved in the corporate adoption and deployment of innovation (Kratzer et al., 2017).

While a wide range of theories and literature recognize the importance of individual (e.g., TAM, Davis et al., 1989; Venkatesh \& Davis, 2000) and organizational (e.g., Frambach \& Schillewaert, 2002) psychological factors, there is not a comprehensive framework that outlines the key psychological factors that influence corporate buyers in the context of organizational technology adoption decisions. Our study responds to this gap and van Oorschot et al.'s (2018) call to examine the cognitive component of the innovation adoption process. We argue that this framework is valuable as it adds to the nascent research area, providing initial indications of the key psychological factors that influence technology adoption decisions. It has been argued that the innovation literature has become fragmented with separate approaches, different models, and organized into domain silos (Keupp et al., 2012; van Oorschot et al., 2018). Rather than offering yet another model, we hope to add to the literature by contributing to a more holistic perspective for innovation adoption that recognizes the fundamental role of psychological elements in this organizational process (Makkonen et al., 2016).

It was developed from data gathered in the oil and gas sector but it has potential applications for technology researchers but also practitioners involved in the buying or selling of new technologies in other business contexts. It is important to understand the full set of psychological factors that can potentially influence technology decisions when engaged in this process or designing interventions to facilitate the uptake of new products and systems.

\section{Industrial Context}

The results essentially highlight the hidden facilitators and blockers that influence technology adoption decisions in industry. In comparison with other sectors, similar psychological themes are identified across industries such as risk aversion (e.g., defence; Greiner \& Franza, 2003), technology attitudes (e.g., IT Systems; Davis et al., 1989; automated driving; Ghazizadeh et al., 2012), and organizational culture (e.g., IT systems, Frambach \& Schillewaert, 2002; and manufacturing (Kratzer et al., 2017). However, given the high risk, high-reliability nature of the oil and gas industry, risk perception, uncertainty, and expertise, as well as how these are managed by leaders and organizations, were found to be particularly pertinent. While there are features that may be specific to the O\&G industry, it would appear that they share characteristics with other industries, such as the high risk, high-reliability nature (e.g., healthcare), financial implications of failure (e.g., banking), automation (e.g., motor manufacturing), increasing governmental focus on the environmental impact (e.g., aviation), and decommissioning (e.g., nuclear power). The upstream $O \& G$ industry is not alone in having a reputation for being slow to uptake new technology. Many sectors (e.g., healthcare) face a similar paradox of needing to embrace innovation to remain competitive but experiencing resistance to technological change (Williams \& Dickinson, 2010). Consequently, understanding the psychological factors that influence corporate decision-makers could have a potential impact, not only for supporting innovation uptake within O\&G but also across the many sectors experiencing digitalization (Nambisan et al., 2019). Consequently, those working outside O\&G may recognize many parallels within our results and find the psychological framework to be valuable for better understanding technology adoption within their own organization.

From the decision-maker perspective, personality characteristics such as innovativeness within individuals' work lives, referred to as an "exploration" trait within O\&G, (Perrons et al., 2018) influence adoption intentions (Tabak \& Barr, 1999). They also appear to be closely related to constructs such as domain-specific innovativeness (Goldsmith \& Hofacker, 1991) and technological innovativeness (Thakur et al., 2016). Further examination of how innovativeness influences technology adoption in O\&G could be valuable, such as has been done for procurement (Steenstra et al., 2020). Within oil and gas, individual- and sector-level risk aversion (OGTC, 2018; Oyovwevto, 2014) have been identified as influencing technology uptake. Given the recent influx of disruptive technologies into this industry (Venables, 2018), it is likely that these risk aversion barriers may be heightened for radical innovations (Assink, 2006; Radnejad \& Vredenburg, 2019).

Risk perception and tolerance are a barrier to technology adoption in the broader innovation literature (Ghadim et al., 2005; Paluch \& Wunderlich, 2016). Several forms of individual and organizational risk were identified in our interviews including financial risk, reputational risk, operational risk, and career risk. These risk factors are closely linked to uncertainty, knowledge, previous experiences, and expectations as well as trust (Barham et al., 2014; Ghadim et al., 2005). Insufficient access to reliable information sources and 
technical knowledge may result in a poor "technical backbone" that negatively impacts subsequent risk perceptions within $\mathrm{O} \& \mathrm{G}$ (Daneshy \& Bahorich, 2005). As in consumer psychology, a well-informed buyer, both at an organizational and individual level, is required to make accurate assessments of the risks and benefits associated with new technology (Damanpour et al., 2018). It is important to note that like many industries, technical knowledge and expertise have been outsourced to service companies within O\&G which may limit the technical knowledge available to accurately make a risk assessment. For example, research and development activities previously undertaken by international operating companies are now typically conducted by service companies, shifting the locus of knowledge (Perrons, 2014).

Organizational culture in the customer organization was identified as a key facilitator for technology adoption, reflecting the wider innovation and business literature (e.g., Frambach \& Schillewaert, 2002; Radnejad et al., 2017). Developing a culture that values innovation and shows readiness toward technology adoption is crucial (Hameed et al., 2012; Rogers, 1995) but this may be at odds with a short-term and cost-centric leadership style that is historically common within the O\&G industry (Damanpour \& Schneider, 2006). Understanding and examining organizational culture in terms of innovation adoption is crucial as aspects of it will likely influence other psychological factors. For example, cultural norms and priories will likely influence technology attitudes, direct individual motivations, and frame risk perceptions. An organization's culture around failure and risk will likely influence perceptions of uncertainty, risk, and motivations. It is also likely that organizational factors, such as organizational culture and leadership, as well as individual factors such as technology attitudes and social influences, will be interrelated with the wider environment of the industry. Consequently, the conservative reputation of the $\mathrm{O} \& \mathrm{G}$ industry (Daneshy \& Bahorich, 2005) will likely frame companies' culture, leader's attitudes, and end-users' perceptions of risk. Being able to measure, benchmark, and improve an organization's technology adoption culture has the potential to be valuable for creating an environment in which innovation is valued and harnessed quicker, not only within organizations but also across industries. It may be beneficial for future research to adapt organizational culture measures (e.g., Hogan \& Coote, 2014; Schein, 1992) to this context.

\section{Limitations and Future Research}

The Psychological Technology Adoption framework which we propose in this article is clearly at a very early stage of development and we appreciate that this would require a significant degree of additional testing before its validity could be fully established. Further examination of the proposed set of 15 factors is part of our ongoing research program as detailed below but we also invite other researchers to apply the framework to their data sets relating to the adoption of new technologies in business, industry, and healthcare. Independent scrutiny would enable the acquisition of the evidence base that would be required in order to determine the internal and external validity of our framework.

With regard to method, interviews can provide rich data, particularly within complex topics, however, they are subjective and prone to bias and other influences (Rowley, 2012). Multiple perspectives about a single reality can support validity
(Golafshani, 2003) but while our UKCS sample represented different roles, company types and backgrounds, alternative samples focussed on other basins (e.g., Gulf of Mexico) might have identified alternative psychological factors. This speaks to a greater issue of qualitative research in terms of validity and generalizability. For example, the specific characteristics of the UKCS (e.g., mature assets) may limit the generalizability of the results to other sectors. However, it should be noted that approximately half of the interviewees had worked, or were currently working, in other O\&G basins (e.g., Gulf of Mexico, South-East Asia, and Australia) which would support a greater level of generalizability. Further research is underway to collect case studies focusing on a sample of new technologies being introduced to the upstream sector. This will use data triangulation with multiple data sources (interviews, observations, and document analysis) to test the validity of our preliminary framework.

The types of technologies developed and deployed within the O\&G may reduce the generalizability of the findings. However, it uses wide range of physical and digital technologies (e.g., robotics, AI, blockchain, predictive analysis, digital twins, augmented reality, and wearable technologies) which are also utilized in many other sectors (e.g., digital twins in aviation; David et al., 2018). In some cases, technologies specifically developed within O\&G have been used in other sectors such as medical science and space exploration (Jacobs, 2019). Furthermore, O\&G is also facing the challenges of digitalization so while there may be aspects of the technologies which are not directly comparable, it is likely that practitioners working in other sectors will face parallel problems using related technologies (e.g., wearable monitoring technologies or automation).

A third limitation is that no attempt was made to assess the relative weightings or interplay of the 14 factors, although we have suggested where they appeared to be influencing each other. In an attempt to examine the weightings of the factors within different contexts (e.g., well-established companies compared to start-ups or traditional technologies compared to clean energy technologies), a scenario-based study is being devised. This quantitative method should provide some evidence for relative factor weightings in adoption decision-making. Methods used to examine the acceptance of sales and distribution software within O\&G in Indonesia (Jingga et al., 2019) and implementation processes in the construction industry (Sepasgozar et al., 2018) may also be valuable for future model building.

In terms of future research avenues, the results suggest that the development of interventions designed to address product champion innovativeness, organizational culture, and leadership could be profitable for technology uptake. One possible angle is to consider how the concept of safety culture was introduced and developed within the $O \& G$ industry, particularly with reference to supporting safety leadership (National Academies of Sciences, 2016). It is possible that some of these cultural development approaches and new behavioral change evidence (Carey et al., 2019) may be adapted to the current challenge of technology adoption. Recognizing the significant impact that positive technology leadership can have could be a valuable first step, particularly by providing guidance and support on understanding how managerial actions drive the technology culture (e.g., developing vision, leadership styles, and clear communication of priorities).

Finally, the current COVID-19 pandemic may provide a considerable stimulus to the adoption of new technologies (Clipper, 2020; 
Juergensen et al., 2020) and it would be interesting to determine how the psychological factors from our framework have an influencing role in technology adoption under rapidly changing demand conditions.

\section{Conclusion}

While the technical characteristics of a technology will strongly influence its success, how people respond to and interact with it will likely have an even stronger impact on how well it is adopted. Thus, understanding how psychological factors influence technology adoption decisions by industrial consumers is vital to support the adoption of innovations not only in $O \& G$ but also across many sectors facing challenges such as digitalization and operating in a post-COVID-19 world. Our interview study identified the key psychological factors that influence new technology uptake decisions in the upstream O\&G industry. This was used to develop the preliminary psychological technology adoption framework consisting of 15 factors within six overarching categories, reflecting those found in a literature review of this sector (Roberts \& Flin, 2020) and industry bodies. While psychological factors are present in many prominent technology acceptance and adoption theories, there does not appear to be a comprehensive model that outlines the key psychological factors that influence corporate buyers in the context of organizational technology adoption decisions. Our framework adds to this nascent research area, providing initial indications of the key psychological factors that influence technology adoption decisions. Further studies will need to be conducted to determine the weightings of the influencing factors and to use these in order to develop explanatory models and then interventions that can support the successful introduction and acceptance of new technology in O\&G. It has potential applications for technology researchers but also for practitioners involved in the buying or selling of new technologies in a business context. Finally, with many industries considering new ways of working, for example, with robotics or digitalization, the generalizability of the psychological factor set, should also be tested.

\section{References}

Afolayan, A., \& de la Harpe, A. (2020). The role of evaluation in SMMEs' strategic decision-making on new technology adoption. Technology Analysis and Strategic Management, 32(6), 697-710. https://doi.org/10.1080/ 09537325.2019.1702637

Agarwal, R., \& Prasad, J. (1999). Are individual differences germane to the acceptance of new information technologies? Decision Sciences, 30(2), 361-391. https://doi.org/10.1111/j.1540-5915.1999.tb01614.x

Ajzen, I. (1991). The theory of planned behavior. Organizational Behavior and Human Decision Processes, 50(2), 179-211. https://doi.org/10.1016/ 0749-5978(91)90020-T

Ajzen, I., \& Fishbein, M. (2005). The influence of attitudes on behavior. In D. Albarracín, B. T. Johnson, \& M. P. Zanna (Eds.), The handbook of attitudes (pp. 173-221). Lawrence Erlbaum.

Aldahdouh, T. Z., Korhonen, V., \& Nokelainen, P. (2019). What contributes to individual innovativeness? A multilevel perspective. International Journal of Innovation Studies, 3(2), 23-39. https://doi.org/10.1016/j.ijis.2019.06.001

American Psychological Association. (n.d.). APA dictionary of psychology. Retrieved July 2020, from https://dictionary.apa.org/psychology

Assink, M. (2006). Inhibitors of disruptive innovation capability: A conceptual model. European Journal of Innovation Management, 9(2), 215-233. https://doi.org/10.1108/14601060610663587
Atkinson, J. W. (1957). Motivational determinants of risk-taking. Psychological Review, 64(6), 359-372. https://doi.org/10.1037/h0043445

Bagozzi, R. (2007). The legacy of the technology acceptance model and a proposal for a paradigm shift. Journal of the Association for Information Systems, 8(4), 244-254. https://doi.org/10.17705/1jais.00122

Barbour, R. (2001). Checklists for improving rigour in qualitative research: A case of the tail wagging the dog? British Medical Journal, 322, 11151117. https://doi.org/10.1136/bmj.322.7294.1115

Barham, B. L., Chavas, J. P., Fitz, D., Salas, V. R., \& Schechter, L. (2014). The roles of risk and ambiguity in technology adoption. Journal of Economic Behavior \& Organization, 97, 204-218. https://doi.org/10 $.1016 /$ j.jebo.2013.06.014

Bartels, J., \& Reinders, M. J. (2011). Consumer innovativeness and its correlates: A propositional inventory for future research. Journal of Business Research, 64(6), 601-609. https://doi.org/10.1016/j.jbusres.2010.05.002

Bazeley, P., \& Jackson, K. (Eds.). (2013). Qualitative data analysis with NVivo. SAGE Publications.

Bazerman, M., \& Moore, D. (2017). Judgment in managerial decision making (8th ed.). Wiley.

Bereznoy, A. (2019). Catching-up with supermajors: The technology factor in building the competitive power of national oil companies from developing economies. Industry and Innovation, 26(2), 127-157. https:// doi.org/10.1080/13662716.2018.1467311

Braun, V., \& Clarke, V. (2006). Using thematic analysis in psychology. Qualitative Research in Psychology, 3, 77-101. https://doi.org/10.1191/ 1478088706qp063oa

Cacciotti, G., Hayton, J. C., Mitchell, J. R., \& Giazitzoglu, A. (2016). A reconceptualization of fear of failure in entrepreneurship. Journal of Business Venturing, 31(3), 302-325. https://doi.org/10.1016/j.jbusvent.2016.02.002

Carey, R., Connell, L., Johnston, M., Rothman, A., de Bruin, M., Kelly, M., \& Michie, S. (2019). Behavior change techniques and their mechanisms of action: A synthesis of links described in published intervention literature. Annals of Behavioral Medicine, 53(8), 693-707.

Carlsen, B., \& Norheim, O. F. (2003). Introduction of the patient-list system in general practice-Changes in Norwegian physicians' perception of their gatekeeper role. Scandinavian Journal of Primary Health Care, 21(4), 209-213. https://doi.org/10.1080/02813430310004155

Clipper, B. (2020). The Influence of the COVID-19 Pandemic on Technology Adoption in Healthcare. Nurse Leader, 18(5), 500-503. https:// doi.org/10.1016/j.mnl.2020.06.008

Cohen, J. (1960). A coefficient of agreement for nominal scales. Educational and Psychological Measurement, 20, 37-46. https://doi.org/10.1177/ 001316446002000104

Corbin, J., \& Strauss, A. (2014). Basics of qualitative research: Techniques and procedures for developing grounded theory. SAGE Publications.

Cullen, D. (1990). The public inquiry into the Piper Alpha disaster (Vol. 1). Department of Energy. Retrieved August 2020, from https://www.hse.gov .uk/offshore/piper-alpha-public-inquiry-volume1.pdf

Damanpour, F., Sanchez-Henriquez, F., \& Chiu, H. H. (2018). Internal and external sources and the adoption of innovations in organizations. British Journal of Management, 29(4), 712-730. https://doi.org/10.1111/14678551.12296

Damanpour, F., \& Schneider, M. (2006). Phases of the adoption of innovation in organizations: Effects of environment, organization, and top managers 1. British Journal of Management, 17(3), 215-236. https:// doi.org/10.1111/j.1467-8551.2006.00498.x

Daneshy, A. A., \& Bahorich, M. S. (2005). Accelerating technology acceptance: overview. In Proceedings of the SPE annual technical conference and exhibition, Dallas, Texas. Society of Petroleum Engineers. Paper Number: SPE-98553-MS. https://doi.org/10.2118/98553-MS

David, J., Lobov, A., \& Lanz, M. (2018). Learning experiences involving digital twins. In IECON 2018-44th annual conference of the IEEE industrial electronics society, Washington, DC, (pp. 3681-3686). IEEE. https://doi.org/10.1109/IECON.2018.8591460 
Davis, F. D., Bagozzi, R. P., \& Warshaw, P. R. (1989). User acceptance of computer technology: A comparison of two theoretical models. Management Science, 35(8), 982-1003. https://doi.org/10.1287/mnsc.35.8.982

Deery, H. (1999). Hazard and risk perception among young novice drivers. Journal of Safety Research, 30, 225-236. https://doi.org/10.1016/S00224375(99)00018-3

Demolombe, R. (2004). Reasoning about trust: A formal logical framework. In C. Jensen, S. Poslad \& T. Dimitrakos (Eds.), Trust Management. iTrust 2004. Lecture Notes in Computer Science (Vol. 2995). Springer. https:// doi.org/10.1007/978-3-540-24747-0_22

Dodgson, M. (2018). Technological collaboration in industry: Strategy, policy, and internationalization in innovation (Vol. 11). Routledge. https://doi.org/10.4324/9781351265607

Edison, S. W., \& Geissler, G. (2003). Measuring attitudes towards general technology: Antecedents, hypotheses, and scale development. Journal of Targeting. Measurement and Analysis for Marketing, 12(2), 137-156. https://doi.org/10.1057/palgrave.jt.5740104

Endsley, M. R. (2017). From here to autonomy: Lessons learned from human-automation research. Human Factors, 59(1), 5-27. https://doi.org/ 10.1177/0018720816681350

Faulkner, S. L., \& Trotter, S. P. (2017). Data saturation. In Matthes, J., Davis, C. S., \& Potter, R. F. (Eds.), The international encyclopaedia of communication research methods. https://doi.org/10.1002/9781118901731.iecrm0060

Fishbein, M., \& Ajzen, I. (1975). Belief, attitude, intention and behaviour: An introduction to theory and research. Addison-Wesley.

Flanagan, J. C. (1954). The critical incident technique. Psychological Bulletin, 51(4), 327-358. https://doi.org/10.1037/h0061470

Fleiss, J. L. (1981). Statistical methods for rates and proportions (2nd ed.). Wiley.

Frambach, R. T., \& Schillewaert, N. (2002). Organizational innovation adoption: A multi-level framework of determinants and opportunities for future research. Journal of Business Research, 55(2), 163-176. https://doi.org/10.1016/S0148-2963(00)00152-1

Gagné, M., \& Deci, E. L. (2005). Self-determination theory and work motivation. Journal of Organizational Behavior, 26(4), 331-362. https://doi.org/10.1002/job.322

Gagnon, Y., \& Toulouse, J. (1996). The behavior of business managers when adopting new technologies. Technological Forecasting and Social Change, 52(1), 59-74. https://doi.org/10.1016/0040-1625(95)00271-5

Ghadim, A. K. A., Pannell, D. J., \& Burton, M. P. (2005). Risk, uncertainty, and learning in adoption of a crop innovation. Agricultural Economics, 33(1), 1-9. https://doi.org/10.1111/j.1574-0862.2005.00433.x

Ghazizadeh, M., Lee, J. D., \& Boyle, L. N. (2012). Extending the technology acceptance model to assess automation. Cognition Technology and Work, 14(1), 39-49. https://doi.org/10.1007/s10111-011-0194-3

Glaser, B. G., \& Strauss, A. L. (2017). Discovery of grounded theory: Strategies for qualitative research. Routledge. https://doi.org/10.4324/ 9780203793206

Golafshani, N. (2003). Understanding reliability and validity in qualitative research. Qualitative Report, 8(4), 597-607.

Goldsmith, R. E., \& Hofacker, C. F. (1991). Measuring consumer innovativeness. Journal of the Academy of Marketing Science, 19(3), 209-221. https://doi.org/10.1007/BF02726497

Greiner, M. A., \& Franza, R. M. (2003). Barriers and bridges for successful environmental technology transfer. The Journal of Technology Transfer, 28(2), 167-177. https://doi.org/10.1023/A:1022998617118

Hameed, M. A., Counsell, S., \& Swift, S. (2012). A conceptual model for the process of IT innovation adoption in organizations. Journal of Engineering and Technology Management, 29(3), 358-390. https://doi.org/10 .1016/j.jengtecman.2012.03.007

Hassani, H., Silva, E. S., \& Al Kaabi, A. M. (2017). The role of innovation and technology in sustaining the petroleum and petrochemical industry. Technological Forecasting and Social Change, 119, 1-17. https://doi.org/ 10.1016/j.techfore.2017.03.003
Hauser, J., Tellis, G. J., \& Griffin, A. (2006). Research on innovation: A review and agenda for marketing science. Marketing Science, 25(6), 687 717. https://doi.org/10.1287/mksc. 1050.0144

Herath, C. S. (2010). Motivation as a potential variable to explain farmers' behavioral change in agricultural technology adoption decisions. $E+M$. Ekonomie a Management, 3, 62-71.

Hogan, S. J., \& Coote, L. V. (2014). Organizational culture, innovation, and performance: A test of Schein's model. Journal of Business Research, 67(8), 1609-1621. https://doi.org/10.1016/j.jbusres.2013.09.007

Huijts, N., Molin, E., \& Steg, L. (2012). Psychological factors influencing sustainable energy technology acceptance: A review-based comprehensive framework. Renewable \& Sustainable Energy Reviews, 16(1), 525531. https://doi.org/10.1016/j.rser.2011.08.018

Hunter, D. (2002). Risk perception and risk tolerance in aircraft pilots (DOT/FAA/AM-02/17). Federal Aviation Administration.

Hurt, H. T., Joseph, K., \& Cook, C. D. (1977). Scales for the measurement of innovativeness. Human Communication Research, 4(1), 58-65. https:// doi.org/10.1111/j.1468-2958.1977.tb00597.x

Jacobs, T. (2019). How oil innovation has benefited other industries. Journal of Petroleum Technology, 71(3), 40-42. https://doi.org/10.2118/03190040-JPT

Jingga, F., Saraswati, D. A., \& Limantara, N. (2019). Evaluation of MySAP sales and distribution module using technology acceptance model (a case study approach at oil and gas company in Indonesia). In 2019 International Conference on Information Management and Technology (ICIMTech; pp. 272-277). IEEE. https://doi.org/10.1109/ICIMTech.2019.8843804

Johnson, B. B., \& Slovic, P. (1995). Presenting uncertainty in health risk assessment: Initial studies of its effects on risk perception and trust. Risk Analysis, 15(4), 485-494. https://doi.org/10.1111/j.1539-6924.1995 .tb00341.x

Juergensen, J., Guimón, J., \& Narula, R. (2020). European SMEs amidst the COVID-19 crisis: Assessing impact and policy responses. Economia e Politica Industriale, 47, 499-510. https://doi.org/10.1007/s40812-02000169-4

Kahneman, D., Lovallo, D., \& Sibony, O. (2011). Before you make that big decision. Harvard Business Review, 89(6), 50-60.

Keupp, M., Palmié, M., \& Gassmann, O. (2012). The strategic management of innovation: A systematic review and paths for future research. International Journal of Management Reviews, 14(4), 367-390. https://doi.org/10 $.1111 / \mathrm{j} .1468-2370.2011 .00321 . x$

Kratzer, J., Meissner, D., \& Roud, V. (2017). Open innovation and company culture: Internal openness makes the difference. Technological Forecasting and Social Change, 119, 128-138. https://doi.org/10.1016/j.techfore .2017.03.022

Lin, Z., \& Filieri, R. (2015). Airline passengers' continuance intention towards online check-in services: The role of personal innovativeness and subjective knowledge. Transportation Research Part E, Logistics and Transportation Review, 81, 158-168. https://doi.org/10.1016/j.tre.2015.07.001

Macdonald, S., \& Williams, C. (1994). The survival of the gatekeeper. Research Policy, 23(2), 123-132. https://doi.org/10.1016/0048-7333(94) 90049-3

Makkonen, H., Johnston, W., \& Javalgi, R. (2016). A behavioral approach to organizational innovation adoption. Journal of Business Research, 69(7), 2480-2489. https://doi.org/10.1016/j.jbusres.2016.02.017

Markham, S., \& Aiman-Smith, L. (2001). Product champions: Truths, myths, and management. Research Technology Management, 44(3), 44-50. https://doi.org/10.1080/08956308.2001.11671429

Mason, J. (2017). Qualitative researching. SAGE Publications.

Mayring, P. (2004). Qualitative content analysis. In U. Flick, E. von Kardoff \& I. Steinke (Eds.), A companion to qualitative research (pp. 266-275). SAGE Publications.

Mero, J., Tarkiainen, A., \& Tobon, J. (2020). Effectual and causal reasoning in the adoption of marketing automation. Industrial Marketing Management, 86, 212-222. https://doi.org/10.1016/j.indmarman.2019.12.008 
Michie, S., Van Stralen, M., \& West, R. (2011). The behaviour change wheel: A new method for characterising and designing behaviour change interventions. Implementation Science; IS, 6(1), 42. https://doi.org/10 $.1186 / 1748-5908-6-42$

Moore, G. C., \& Benbasat, I. (1991). Development of an instrument to measure the perceptions of adopting an information technology innovation. Information Systems Research, 2(3), 192-222. https://doi.org/10 $.1287 /$ isre. 2.3.192

Nambisan, S., Wright, M., \& Feldman, M. (2019). The digital transformation of innovation and entrepreneurship: Progress, challenges, and key themes. Research Policy, 48(8), 103773. https://doi.org/10.1016/j.respol.2019.03.018

National Academies of Sciences, Engineering, and Medicine. (2016). Strengthening the safety culture of the offshore oil and gas industry. The National Academies Press. https://doi.org/10.17226/23524.

Nochur, K. S., \& Allen, T. J. (1992). Do nominated boundary spanners become effective technological gatekeepers? (technology transfer). IEEE Transactions on Engineering Management, 39(3), 265-269. https:// doi.org/10.1109/17.156560

Noke, H., Perrons, R. K., \& Hughes, M. (2008). Strategic dalliances as an enabler for discontinuous innovation in slow clock speed industries: Evidence from the oil and gas industry. $R \& D$ Management, 38(2), 129-139. https://doi.org/10.1111/j.1467-9310.2008.00505.x

Northouse, P. (2018). Leadership: Theory and practice. SAGE Publications. O'Connor, C., \& Joffe, H. (2020). Intercoder reliability in qualitative research: Debates and practical guidelines. International Journal of Qualitative Methods, 19, 1-13. https://doi.org/10.1177/1609406919899220

Oil and Gas Authority. (2018). Technology INSIGHTS REPORT (April). Retrieved January 2020, from https://www.ogauthority.co.uk/newspublications/publications/2018/technology-insights-report/

Oil and Gas Technology Centre. (2018). Application of data analytics technologies to improve asset operations and maintenance: Digital landscaping study of the oil and gas sector. Retrieved January 2020, from https://www.theogtc.com/media/2380/digital-landscaping-study-ofthe-oil-and-gas-sector-application-of-data-analytics-technologies-to-improveasset-operations-and-maintenance.pdf

Opdenakker, R. (2006). Advantages and disadvantages of four interview techniques in qualitative research. Forum qualitative sozialforschung/ forum: Qualitative Social Research, 7, 4.

Oyovwevto, J. S. (2014). The social construction of technological innovation in the oil and gas industry [DBA Thesis]. Aberdeen Business School, Robert Gordon University.

Pak, J., Li, L., \& Chung, G. H. (2019). A holistic approach to individual-level innovation implementation. Innovation, 21(4), 552-571. https://doi.org/ 10.1080/14479338.2019.1632710

Paluch, S., \& Wunderlich, N. (2016). Contrasting risk perceptions of technology-based service innovations in inter-organizational settings. Journal of Business Research, 69, 2424-2431. https://doi.org/10.1016/j .jbusres.2016.01.012

Pavlou, P. A. (2003). Consumer acceptance of electronic commerce: Integrating trust and risk with the technology acceptance model. International Journal of Electronic Commerce, 7(3), 101-134. https://doi.org/10.1080/ 10864415.2003.11044275

Perrons, R. K. (2014). How innovation and R\&D happen in the upstream oil \& gas industry: Insights from a global survey. Journal of Petroleum Science Engineering, 124, 301-312. https://doi.org/10.1016/j.petrol.2014.09.027

Perrons, R. K., Burgers, H., \& Newton, C. (2018, September). Who are the innovators in the upstream oil \& gas industry? Insights from the 2017 SPE global innovation survey. In SPE Annual technical conference proceedings. Society of Petroleum Engineers.

Porter, M. E. (1985). Technology and competitive advantage. The Journal of Business Strategy, 5(3), 60-78. https://doi.org/10.1108/eb039075

QSR International. (2013). Nvivo 11 for Windows 10 [Computer software]. Retrieved September 2018, from http://www.qsinternational.com/ products_nvivo.aspx.
Radnejad, A. B., \& Vredenburg, H. (2019). Disruptive technological process innovation in a process-oriented industry: A case study. Journal of Engineering and Technology Management, 53, 63-79. https://doi.org/ 10.1016/j.jengtecman.2019.08.001

Radnejad, A. B., Vredenburg, H., \& Woiceshyn, J. (2017). Meta-organizing for open innovation under environmental and social pressures in the oil industry. Technovation, 66, 14-27. https://doi.org/10.1016/j.technovation 2017.01.002

Ratnasingam, P. (2005). Trust in inter-organizational exchanges: A case study in business to business electronic commerce. Decision Support Systems, 39(3), 525-544. https://doi.org/10.1016/j.dss.2003.12.005

Rau, D., \& Haerem, T. (2010). Applying an organizational learning perspective to new technology deployment by technological gatekeepers: A theoretical model and key issues for future research. Information Systems Frontiers, 12(3), 287-297. https://doi.org/10.1007/s10796-009-9194-8

Roberts, R., \& Flin, R. (2019). The psychological factors that influence successful technology adoption in the oil and gas industry. In Proceedings of the human factors and ergonomics society annual meeting, Seattle, November (Vol. 63, No. 1, pp. 1183-1187). SAGE Publications.

Roberts, R., \& Flin, R. (2020). Unlocking the potential: Understanding the psychological factors that influence technology adoption in the upstream oil and gas industry. SPE Journal, 25, 515-528. https://doi.org/10.2118/ 198903-PA

Rogers, E. (1983), Diffusion of innovations (3rd ed.) The Free Press.

Rogers, E. M. (1995). Diffusion of Innovations: modifications of a model for telecommunications. Die diffusion von innovationen in der telekommunikation, 25-38.

Roupas, P. (2008). Human and organisational factors affecting technology uptake by industry. Innovation, 10(1), 4-28. https://doi.org/10.5172/impp 453.10.1.4

Rowley, J. (2012). Conducting research interviews. Management Research Review, 35, 260-271. https://doi.org/10.1108/01409171211210154

Sauner-Leroy, J. B. (2004). Managers and productive investment decisions: the impact of uncertainty and risk aversion. Journal of Small Business Management, 42(1), 1-18. https://doi.org/10.1080/10864415.2003 .11044275

Schein, E. H. (1992). Organizational culture and leadership. JosseyBass Inc.

Schneider, S., \& Sunyaev, A. (2016). Determinant factors of cloud-sourcing decisions: Reflecting on the IT outsourcing literature in the era of cloud computing. Journal of Information Technology, 31(1), 1-31. https:// doi.org/10.1057/jit.2014.25

Sepasgozar, S. M., Davis, S. R., Li, H., \& Luo, X. (2018). Modelling the implementation process for new construction technologies: Thematic analysis based on Australian and US practices. Journal of Management Engineering, 34(3), 05018005. https://doi.org/10.1061/(ASCE)ME.1943-5479.0000608

Sethna, Z., \& Blythe, J. (2016). Consumer behaviour. SAGE Publications. Shimamoto, D., Yamada, H., \& Wakano, A. (2018). The effects of risk preferences on the adoption of post-harvest technology: Evidence from rural Cambodia. The Journal of Development Studies, 54(10), 1819-1837. https://doi.org/10.1080/00220388.2017.1329527

Slovic, P. (1987). Perception of risk. Science, 236(4799), 280-285. https:// doi.org/10.1126/science.3563507

Steenstra, N., Gelderman, C., Schijns, J., \& Semeijn, J. (2020). Supplier contribution to buyer innovativeness: The influence of customer attractiveness and strategic fit. International Journal of Innovation Management, 24(02), 2050016. https://doi.org/10.1142/S1363919620500164

Stenbacka, C. (2001). Qualitative research requires quality concepts of its own. Management Decision, 7, 551-556. https://doi.org/10.1108/ EUM0000000005801

Streletskaya, N., Bell, S., Kecinski, M., Li, T., Banerjee, S., Palm-Forster, L., \& Pannell, D. (2020). Agricultural adoption and behavioral economics: Bridging the gap. Applied Economic Perspectives and Policy, 42(1), 54 66. https://doi.org/10.1002/aepp.13006 
Tabak, F., \& Barr, S. H. (1999). Propensity to adopt technological innovations: The impact of personal characteristics and organizational context. Journal of Engineering and Technology Management, 16(3-4), 247-270. https://doi.org/10.1016/S0923-4748(99)00011-9

Tabrizi, B., Lam, E., Girard, K., \& Irvin, V. (2019). Digital transformation is not about technology. Harvard Business Review. https://hbr.org/2019/03/ digital-transformation-is-not-about-technology

Thakur, R., Angriawan, A., \& Summey, J. H. (2016). Technological opinion leadership: The role of personal innovativeness, gadget love, and technological innovativeness. Journal of Business Research, 69(8), 2764-2773. https://doi.org/10.1016/j.jbusres.2015.11.012

Tornatzky, L., \& Fleischer, M. (1990). The process of technology innovation. Lexington Books.

van Oorschot, J. A., Hofman, E., \& Halman, J. I. (2018). A bibliometric review of the innovation adoption literature. Technological Forecasting and Social Change, 134, 1-21. https://doi.org/10.1016/j.techfore.2018.04.032

Venables, M. (2018). The growing force of digital disruptions sweep through the oil and gas industry. https://www.forbes.com/sites/markvenables/ 2018/05/30/the-growing-force-of-digital-disruptions-sweeps-throughthe-oil-and-gas-industry/\#7128e08e6d58

Venkatesh, V., \& Davis, F. D. (2000). A theoretical extension of the technology acceptance model: Four longitudinal field studies. Management Science, 46(2), 186-204. https://doi.org/10.1287/mnsc.46.2.186.11926
Wang, R. T., \& Lin, C. P. (2012). Understanding innovation performance and its antecedents: A socio-cognitive model. Journal of Engineering and Technology Management, 29(2), 210-225. https://doi.org/10.1016/j.je ngtecman.2012.01.001

Williams, I., \& Dickinson, H. (2010). Can knowledge management enhance technology adoption in healthcare? A review of the literature. Evidence \& Policy: A Journal of Research. Debate and Practice, 6(3), 309-331. https://doi.org/10.1332/174426410X524811

Wood, I. (2014). UKCS Maximising recovery review: Final report Retrieved September 2018, from https://www.ogauthority.co.uk/media/ 1014/ukcs_maximising_recovery_review.pdf

Xia, D., Zhang, M., Yu, Q., \& Tu, Y. (2019). Developing a framework to identify barriers of Green technology adoption for enterprises. Resources, Conservation and Recycling, 143, 99-110. https://doi.org/10.1016/j.re sconrec.2018.12.022

Yoo, S., \& Kim, B. (2018). A decision-making model for adopting a cloud computing system. Sustainability, 10(8), 2952. https://doi.org/10.3390/ su10082952

ZoBell, S. (2018). Why digital transformations fail: Closing the $\$ 900$ billion hole in enterprise strategy. Forbes. Retrieved January 2020, from https://www.forbes.com/sites/forbestechcouncil/2018/03/13/why-digitaltransformations-fail-closing-the-900-billion-hole-in-enterprise-strategy/ \#787d9c837b8b

\section{Appendix A}

\section{Interview Schedule}

Each interview will take 45 min to an hour and will ask about your job, your experiences of new technology in the UKCS oil and gas sector, and what you feel the key human factor barriers are in relation to technology deployment and adoption. It will also include talking through an example of getting a new technology deployed or adopted either internally within your own organization or within the market generally. You will be asked to discuss the barriers and facilitators that impacted your experience.

\section{General Questions}

1. Can you tell me your job title and a bit about your role within your organization?

a. How does this relate to technology innovation/ adoption?

2. How many years have you been doing that job? (may want to know about previous job (s) if relevant)

a. Have you worked in any sectors outside of oil and gas? (See Q9 Later)

b. Have you worked in any other continental shelves other than the UKCS? (See Q4a)

3. Before we get started, it would be helpful to discuss what technology deployment and adoption mean to you. A common distinction is that deployment is typically driven by the people enforcing it (i.e., an organizational action) while adoption is by the people embracing it (i.e., an enduser level action). (Only use at the beginning of interviews to establish working definitions.) a. Do you agree with this distinction?

b. Are there any other distinctions or phrases that you commonly use in your company?

c. If this distinction does not fully fit, can you suggest a better term to describe the process?

4. Can you tell me about your experiences in relation to new technology in the UKCS?

a. If you have worked outside the UKCS, can you tell me (a) where, (b) how technology deployment and adoption is dealt with, and (c) how this compares with the UKCS?

5. More specifically, can you tell me about your experiences in relation to technology deployment at the sector and organizational level?

a. What do you think the general barriers to technology deployment are?

b. More specifically what psychological factors are there (e.g., risk aversion, attitudes, motivations, culture, norms)?

6. Using your definitions (see Q3), what do you think the difficulties are for end-user adoption of new technology deployment?

a. More specifically what psychological factors are there (e.g., risk aversion, attitudes, motivations, culture, and norms)? 
7. What do you think the prevailing attitude is toward technology deployment and adoption in the UKCS?

a. Is this different from other continental shelves?

8. Risk is frequently discussed in terms of technology adoption and deployment, what types of risks do you think there are from your perspective? (e.g., financial, social, and job security)

a. To what extent are the barriers/attitudes different for deployment compared to adoption?

b. To what extent are human factors a barrier in technology deployment and adoption in the UKCS?

9. If you have worked outside Oil and Gas, can you tell me how that sector responds to technology deployment and adoption, and how this is compared to $\mathrm{O} \& \mathrm{G}$ ?

a. In terms of adoption and deployment?

\section{Technology Adoption Event/Example}

Can you now think of a time in which you were involved in getting a piece of new technology deployed (organizational perspective) or adopted (individual perspective) on UKCS? It can be internal or external technology innovation, as a company deploying new technology within the market, from an innovation managerial role, or from an end-user adoption perspective.

10. Can you tell me in your own words what happened (e.g., a rough time line)?

a. Was this a piece of radical or incremental innovative technology?

b. Do you feel that it was successful?

11. What do you think helped in this experience (facilitators)?
12. What do you think made the deployment difficult (barriers)?

13. What do you think made the adoption difficult (barriers)?

14. For the aspects that did not go so well, what do you think was the cause?

15. What do you think that you learned from the event?

16. In what way was $\mathrm{XX}$ (risk aversion, culture, motivations, psych factors) important to the outcome of the event? (Describe why.)

\section{Moving Forward}

Thinking about the future of technology adoption and deployment in the UKCS.

17. Can you tell me what you think the general trend of technology deployment in the oil and gas industry will be in the next $2-5$ years?

a. What types of technology will be successfully adopted?

b. What barriers stand in the way?

18. In your own words, what do you think would help support technology deployment and adoption?

a. At a sector level

b. At an organizational level

c. At an end-user level

19. Can you tell me if there any practical day-to-day improvements that would help you in terms of technology deployment and/or adoption?

Thank you for answering my questions. Do you have anything that you would like to ask?

\section{Appendix B}

\section{Initial Coding Scheme}

Once a systematic review of the data had been completed, an initial coding scheme was produced to represent the psychological factors. At this stage, items of data were coded with many codes that appeared to fit the data until definitions had been determined. A total of 38 codes was identified and is shown below. It should be noted that this was refined during the course of the thematic analysis and so is not exactly the same as the framework given in the results section.

\begin{tabular}{ll}
\hline \multicolumn{1}{c}{ Category } & \multicolumn{1}{c}{ Factor } \\
\hline Personality factors & Innovativeness \\
& Risk aversion \\
& Risk taker \\
& Openness to change \\
& Conservative \\
Motivation factors & Personal incentives \\
& Fear of technology failure \\
& Job security \\
& Pay/promotion
\end{tabular}


Appendix B (continued)

\begin{tabular}{|c|c|}
\hline Category & Factor \\
\hline \multicolumn{2}{|l|}{ Attitude factors } \\
\hline & Technology attitudes \\
\hline & Trust \\
\hline & Not invented here syndrome \\
\hline & Engineering mindset \\
\hline & Scepticism \\
\hline \multicolumn{2}{|l|}{ Cognitive factors } \\
\hline & Risk perception \\
\hline & Technical knowledge \\
\hline & Perceptions of certainty \\
\hline & Previous experience \\
\hline & Decision-making \\
\hline & Expectations \\
\hline & Workload \\
\hline \multicolumn{2}{|l|}{ Social factors } \\
\hline & Social influence \\
\hline & Subjective norms \\
\hline & Image \\
\hline & Team \\
\hline & Group effect \\
\hline & Herd mentality \\
\hline \multicolumn{2}{|c|}{ Organizational factors } \\
\hline & Leadership \\
\hline & Collaboration culture \\
\hline & Technology adoption culture \\
\hline & Management \\
\hline & Change management procedures \\
\hline & Risk management \\
\hline & Bonuses \\
\hline \multirow[t]{4}{*}{ Additional codes } & Industry characteristics \\
\hline & HSE and government regulations \\
\hline & Budgets \\
\hline & Risk aversion (industry) \\
\hline
\end{tabular}

\section{Appendix C}

\section{Interrater Reliability Test}

The interrater reliability (IRR) test was conducted using the features available within Nvivo 11(QSR International, 2013). This provides support for conducting the test by allowing an IRR to be calculated individually for each combination of node (e.g., psychological factor) and file (e.g., interview transcript X) by conducting a series of coding comparisons. These can then be exported and used to calculate Cohen's Kappa within the Nvivo Coding Comparisons Spreadsheet. These Nvivo calculations were used to calculate the Kappa coefficient across the 37 interviews and all the nodes. These calculations were then applied to the comparisons spreadsheet to calculate the average coefficient weighted by source size. For more information, see: http://help-nv11.qsrinternational.com/desktop/ procedures/run_a_coding_comparison_query.htm

Received March 18, 2020

Revision received October 7, 2020

Accepted November 21, 2020 